\title{
KEANEKARAGAMAN KANTONG SEMAR (Nepenthes spp) PADA SEMAK BELUKAR DAN AREAL TERBUKA DI KEBUN RAYA SAMBAS KABUPATEN SAMBAS KALIMANTAN BARAT
}

\author{
(Diversity of Kantong Semar (Nepenthes spp) in Shrubs and Open Area in Sambas Botanical \\ Garden Sambas Regency West Kalimantan)
}

\author{
Rinny Yuniarty, Iswan Dewantara, Ratna Herawatiningsih \\ Fakultas Kehutanan Universitas Tanjungpura Pontianak. J1. Daya Nasional Pontianak 78124 \\ Email : yuniartyrinny@gmail.com
}

\begin{abstract}
Sambas Botanical Garden is a conservation forest area that has a high diversity of flora and one of them is the Kantong Semar (Nepenthes spp). Research aims; (1) conducting a study of the species diversity of Kantong Semar (Nepenthes spp) in shrubs and open areas in the Sambas Botanical Garden, (2) Study to changes in the composition of Kantong Semar species (Nepenthes spp) in Sambas Botanical Garden, (3) determining species composition and dominant of kantong semar (Nepenthes spp) that grows in shrubs and open areas. This research was conducted by a survey method in which the laying of observation plots by purposive sampling. The results of the study showed that the species diversity of Kantong Semar (Nepenthes spp) in the Sambas Botanical Garden was a low category with a value of 0.254 in shrubs and an open area of 0.01756. There was a change in the composition of the Kantong Semar species after two years of previous research. The change occurred where two new species of N. xneglecta and N.gracilis Korth that grown in Sambas Botanical Garden. Based on the results of morphological analysis, we found as many as 5 species of Kantong Semar consisting of N. mirabilis (Lour) Druce, N.gracilis Korth, N.ampullaria Jack, N. xneglecta, N. xhookeriana, which grow in shrubs, and N. mirabilis (Lour) in open area. The results of the analysis of the Importance Value Index (INP) that dominant species are N.ampullaria Jack with a value of 107.02 and N. xhookeriana 33.32 where both species of Kantong Semar grown in the shrub area.
\end{abstract}

Keywords: Kantong semar (Nepenthes spp), shrubs and open area, Species diversity.

\section{PENDAHULUAN}

Kalimantan merupakan salah satu pusat penyebaran kantong semar (Nepenthes spp) di Indonesia. Jenis tanaman ini dapat tumbuh memanjang, menggemuk, dan berbentuk seperti umbi, atau menyerupai gelas piala. Kantong semar bukan merupakan bunga, melainkan daun yang mengalami modifikasi untuk menahan air. Setiap tanaman kantong semar dapat mempunyai 2-3 macam kantong yang berbeda bentuknya, sesuai dengan kondisi alam dan habitatnya.
Menurut Firstantinovi dan Karjono (2006), terdapat 103 jenis kantong semar (Nephentes spp) yang telah teridentifikasi dan dipublikasikan. Sebanyak 64 jenis terdapat di Indonesia dan sebanyak 29 jenis terdapat di pulau Borneo (Anwar et.all, dalam Sartika dkk, 2017).

Keberadaan kantong semar di alam sebenarnya merupakan bagian yang cukup penting dalam suatu ekosistem. Tumbuhan ini menjadi sumber penyedian nectar bagi serangga-serangga yang hidup di sekitarnya di samping berfungsi sebagai 
tempat hidup beberapa jenis serangga seperti semut dan nyamuk. Oleh sebab itu, perilaku tumbuh organ-organ kantong semar banyak disesuaikan dengan fungsinya. Di dalam cairan kantong terdapat interaksi antara mikrobia dan hewan-hewan kecil yang hidup di dalam kantong (Phillipps dan Lamb, 1996).

Kebun Raya Sambas memiliki luas areal sekitar 300 Ha terletak di Desa Sabung Kecamatan Subah Kabupaten Sambas. Kebun Raya ini merupakan kawasan hutan konservasi yang memiliki keanekaragaman flora yang tinggi dan salah satu diantaranya adalah kantong semar (Nepenthes spp). Berdasarkan kajian sebelumnya, di lokasi ini di ketahui terdapat beranekaragam jenis (Nepenthes spp). Hasil pengamatan di lapangan bahwa kantong semar (Nepenthes spp) yang terdapat di Kebun Raya tersebut tumbuh atau hidup pada semak belukar dan tempat terbuka.

Hasil penelitian Hairrunisa, Dewantara, dan Hardian (2018) yang dilaksanakan pada tahun 2017 menunjukkan bahwa kantong semar yang terdapat di Kebun Raya Sambas sebanyak 5 jenis. Jenis tanaman ini terus berkembang atau mengalami perubahan seiring dengan pertambahan waktu dan kondisi habitatnya. Selama dua tahun di duga terjadi perubahan keanekaragaman jenis kantong semar yang terdapat di Kebun Raya tersebut. Permasalahnya bagaimana perubahan keanekaragaman jenis kantong semr (Nepenthes spp) dalam kurun waktu selama dua tahun. Apakah terjadi penambahan atau pengurangan serta pergantian jenis dalam kurun waktu dua tahun tersebut di semak belukar dan areal terbuka. Berdasarkan permasalahan tersebut perlu dilakukan studi kembali mengenai keanekaragaman jenis kantong semar (Nepenthes spp) yang terdapat di Kebun Raya Sambas Kabupaten Sambas.

Penelitian ini bertujuan : (1) melakukan studi mengenai keanekaragaman jenis kantong semar ( Nepenthes spp) yang terdapat pada areal semak belukar dan areal terbuka di Kebun Raya Sambas, (2) mengkaji perubahan komposisi jenis kantong semar (Nepenthes spp) di Kebun Raya Sambas dan (3) menentukan perbedaan jenis Kantong semar yang terdapat di daerah semak belukar dan daerah terbuka.

\section{METODE PENELITIAN}

Penelitian dilakukan di Kebun Raya Sambas Kecamatan Subah Kabupaten Sambas Kalimantan Barat menggunakan metode survey dengan peletakan petak pengamatan secara purposive sampling, Petak utama dengan ukuran $10 \mathrm{~m}$ x $10 \mathrm{~m}$ dan di dalamnya dibuat anak petak ukuran $2 \mathrm{~m} \times 2 \mathrm{~m}$ sebanyak 25 buah petak. Teknik pengumpulan data dilakukan dengan mencatat seluruh jenis kantong semar (Nepenthes spp) yang terdapat dalam semak belukar dan tempat yang terbuka pada seluruh petak pengamatan ukuran $2 \mathrm{~m}$ x $2 \mathrm{~m}$. Setiap kantong semar yang ditemukan, difoto dan dicatat karakteristik morfologinya yang terdiri dari daun, batang, kantong, warna kantong, akar, tendril, tempat hidup serta pola tumbuhnya menggantung (upper pitcher) dan dibawah (lower pitcher), Selanjutnya dari kharakterisitk tersebut, diidentifikasi dengan menggunakan buku 
Identifikasi Karangan Dr.Clarke " Pitcher Plants Of Sarawak". Data yang yang dikumpulkan dalam penelitian ini adalah jumlah kantong semar (Nepenthes sp) dan frekuansi keberadaannya dalam setiap petak ukuran $2 \mathrm{~m} \times 2 \mathrm{~m}$. Analisis data dilakukan dengan menghitung Indeks Nilai Penting (INP), Keanekaragaman Jenis ( $\dot{H}$ ), Indeks Dominansi (C), Indeks Kelimpahan Jenis (E), dan Indeks kesamaan Jenis (IS).

\section{HASIL DAN PEMBAHASAN}

Jumlah Jenis dan Individu

Hasil penelitian di kawasan Kebun

Raya Sambas Kecamatan Subah
Kabupaten Sambas hanya menemukan sebanyak 4 petak mengandung kantong semar dari 24 petak. Pada keempat petak tersebut terdapat sebanyak 478 individu kantong semar (Nepenthes spp). Dalam petak tersebut ditemukan sebanyak 5 jenis kantong semar (Nepenthes spp) terdiri dari :N. mirabilis (Lour) Druce, N.gracilis Korth, N.ampullaria Jack, N. x-neglecta, N. x-hookeriana. Jumlah setiap jenis kantong semar (Nepenthes spp) pada empat petak di lokasi Kebun Raya Sambas dapat dilihat pada Tabel 1.

Tabel 1. Jumlah dan Jenis Kantong Semar (Nepenthes spp) Yang Terdapat di Kawasan Kebun Raya Sambas (Number and species of Kantong Semar (Nepenthes spp) Available in the Sambas Botanical Garden Area)

\begin{tabular}{|c|c|c|c|c|c|}
\hline \multirow{2}{*}{ No } & \multirow{2}{*}{ Nama Jenis } & \multirow{2}{*}{$\begin{array}{l}\text { Jumlah } \\
\text { Individu }\end{array}$} & \multicolumn{2}{|c|}{ Jumlah/Kondisi Tapak } & \multirow{2}{*}{ Keterangan } \\
\hline & & & Dalam Semak & Terbuka & \\
\hline 1 & N. mirabilis (Lour) Druce & 10 & 5 & 5 & $\begin{array}{c}\text { Memanjat dan } \\
\text { Teresterial }\end{array}$ \\
\hline 2 & N. gracilis Korth & 2 & 2 & - & Memanjat \\
\hline 3 & N. ampullaria Jack & 375 & 375 & - & $\begin{array}{c}\text { Teresterial dan } \\
\text { Memnjat }\end{array}$ \\
\hline 4 & N. xneglecta & 2 & 2 & - & Teresterial \\
\hline 5 & N. xhookeriana & 89 & 89 & - & $\begin{array}{c}\text { Teresterial dan } \\
\text { Memanjat }\end{array}$ \\
\hline & Jumlah & 478 & 473 & 5 & \\
\hline
\end{tabular}

Hasil penelitian pada Tabel 1 menunjukan N. mirabilis (Lour) Druce ditemukan sebanyak 5 individu yang tumbuh teresterial dan memanjat pada semak belukar dan 5 individu terbuka. Nepenthes gracilis Korth sebanyak 2 individu dengan pola tumbuh memanjat terdapat pada petak 1. Nepenthes ampullaria Jack sebanyak 375 individu dengan tumbuh teresterial dan memanjat terdapat pada petak 2 dan petak 3. Nepenthse xneglecta berjumlah
2 individu tumbuh teresterial merambat di permukaan tanah terdapat pada petak 2. Lokasi tempat tumbuh dan pola tumbuh (memanjat dan teresterial) dapat dilihat pada Gambar 1 dan 2. Nepenthes $x$-hookeriana berjumlah 89 individu dengan pola tumbuh teresterial dan memanjat terdapat pada petak 2. Dari hasil pengamatan jenis N.ampullaria Jack memiliki jumlah individu paling banyak yang ada di Kebun Raya Sambas. Berdasarkan penelitian 
terdahulu Hairunnisah (2018) ditemukan 5 jenis kantong semar, namun dengan jenis yang berbeda. Penelitiannya menemukan Nepenthes ampullaria Jack, Nepenthes rafflesiana

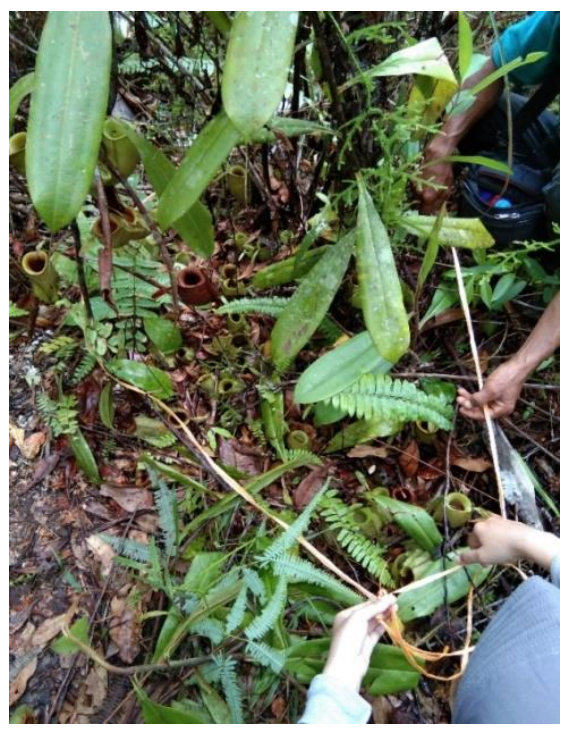

(a)
Jack, Nepenthes $x$-hookeriana, Nepenthes reindwardtiana Miq, Nepenthes mirabilis Druce dengan jumlah 67 individu.

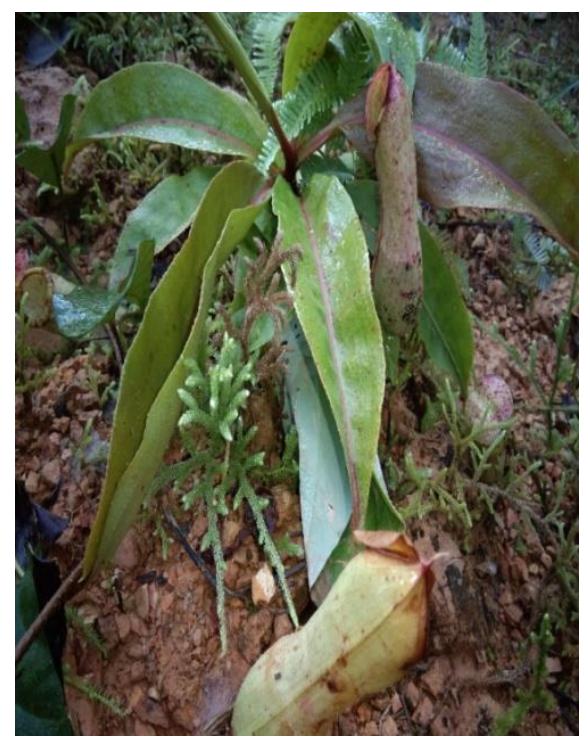

(b)

Gambar 1. Kantong semar (Nepenthes spp) yang tumbuh dalam semak (a) dan tempat terbuka (b) (Kantong semar (Nepenthes spp) growing in bush (a) and open area $(b))$

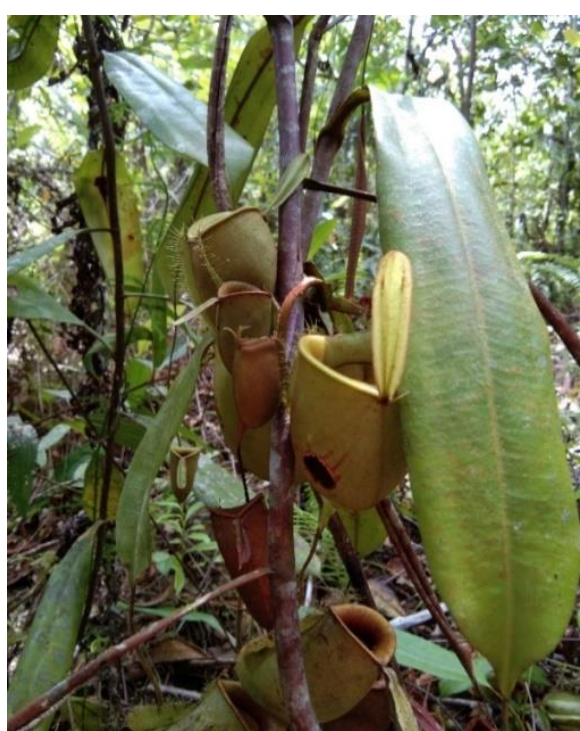

(a)

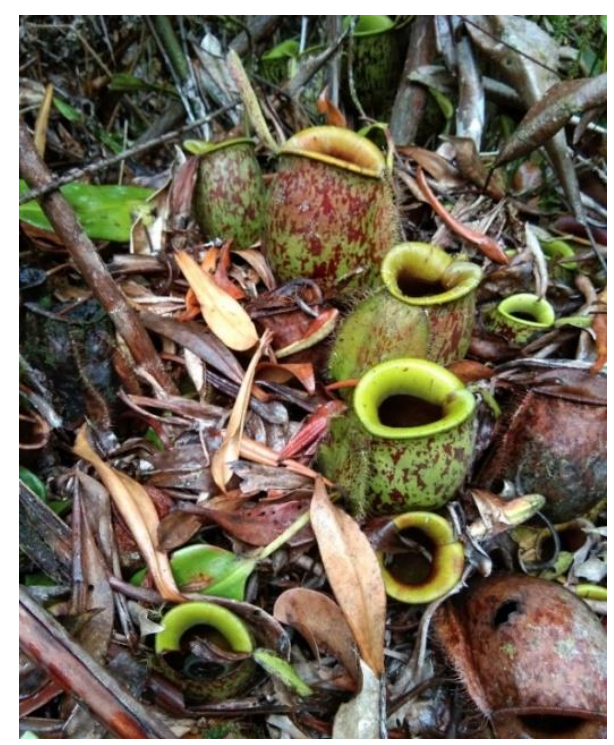

(b)

Gambar 2. Kantong semar (Nepenthes spp) yang tumbuh memanjat (a) dan terresterial (b) (Kantong semar (Nepenthes spp) growing up (a) and terrestrial (b)) 
Kantong semar N.mirabilis (Lour) Druce merupakan jenis yang terdapat di habitat semak belukar berupa pakupakuan resam, soma dan simpur, dengan tutupan tajuk tidak begitu rapat. Pada penelitian ini didapati 3 variasi kantong semar yaitu bentuk silinder, corong pada semak belukar dan pinggang pada areal terbuka serta tumbuh secara teresterial (diatas permukaan tanah). Warna kantong ada yang merah kombinasi hijau, dan hanya berwarna hijau namun memiliki serat serta bercak berwarna merah di sekitar kantong (Gambar 3a). Tutup kantong berwarna merah dan berbentuk oval. Letak kantong diatas permukaan tanah pada jenis kantong semar dengan pola teresterial dan pada pohon untuk yang pola memanjat.

Kantong semar $N$. gracilis Korth merupakan jenis yang dapat dijumpai pada habitat semak belukar. Dimana tempat tumbuhnya berdampingan dengan N.mirabilis (Lour) Druce. Menurut Dino (2016), N. gracilis Korth dan N.mirabilis (Lour) Druce tempat hidup kedua jenis tersebut berdampingan. Jenis kantong semar ini tumbuh Memanjat di pohon soma sampai ketinggian $5 \mathrm{~m}$. Nepenthes gracilis Korth umuya memiliki bentuk kantong silinder, corong dan pinggang. Namun pada penelitian ini hanya di temukan silinder. Jenis kantong sear ini bewarna merah maroon dengan sedikit warna hijau di bagian bawah kantong (Gambar 3b). Pola kantong semar ini ada yang tersterial dan memanjat pada pohon soma..
Kantong semar $N$. ampullaria Jack merupakan jenis yang juga terdapat pada habitat semak belukar yang terdiri dari paku-pakuan resam, soma dan simpur, sawah, tanah-tanah yang basah. Jenis ini tumbuh subur pada habitat dengan tutupan tajuk tidak begitu rapat. Nepenthes ampullaria Jack memiliki bentuk kantong bulat, kendi, atau tempayan. Jenis ini memiliki kantong bewarna hijau yang terletak di permukaan tanah (Gambar 3c), namun terdapat perbedaan antara yang di permukaan tanah dan yang merambat di pohon. Mulut kantong $N$. ampularia berbentuk oval dengan bibir melebar menghadap kearah dalam, dan tutup kantong berbentuk lonjong dan serta bewarna sama dengan kantongnya. Terdapat perbedaan warna kantong antara di permukaan tanah dan kantong yang merambat di pohon. Warna kantong semar yang tumbuh di tanah agak lebih hijau dengan tekstur mulus, sedangkan yang menjalar di pohon bewarna hijau agak kasar. Perbedaan warna ini diduga karena faktor lingkungan yaitu sinar matahari, sehingga kulit kantong agak mengering dengan tekstur kasar.

Kantong semar N. xneglecta merupakan jenis yang berasal dari persilangan antara $N$. gracilis dan $N$. mirabilis . Nepenthes xneglecta dapat ditemukan di habitat semak belukar yang di dominasi oleh paku-pakuan. Umumnya bentuk kantong menyerupai $N$. gracilis, namun,ukurannya lebih besar dibandingkan $N$. xneglecta. Ukuran daun $N$. gracilis lebih panjang 
dan lebar. Warna kantong merah maron mirip seperti N.gracilis namun ukuran kantong lebih kecil (Gambar 3d). Letak kantong merambat di atas permukaan tanah. Terdapat bunga atau calon anakan kantong baru. Keadaan lokasi di temukannya jenis N.xneglecta ketinggian 26 suhu $27{ }^{0} \mathrm{C}$ dengan kelembapan tinggi $84 \%$.

Kantong semar $N$. xhookeriana adalah hasil dari persilangan alam $N$. ampullaria dan $N$. rafflesiana dimana sifat dominan dari kedua induknya sangat terlihat pada jenis ini. Kantong bulat tempayan seperti Nepenthes ammpularia dan bercak atau warna corak seperti N.rafflesiana dan tutupan kantongnya mirip dengan Nepenthes ammpularia (Gambar 3e). N. xhookeriana ketinggian 26 suhu $27{ }^{0} \mathrm{C}$ dengan kelembapan tinggi $84 \%$.

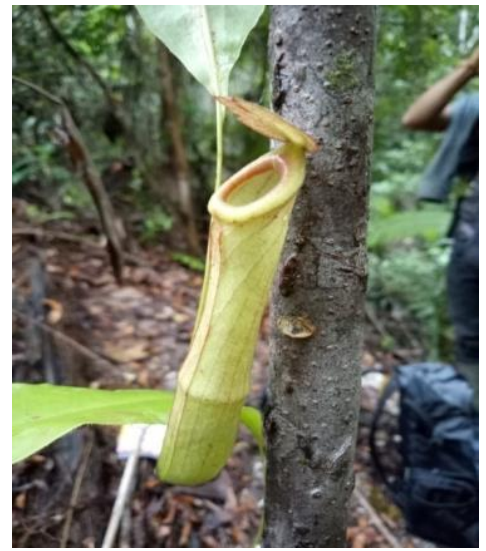

N.mirabilis (Lour) Druce

(a)

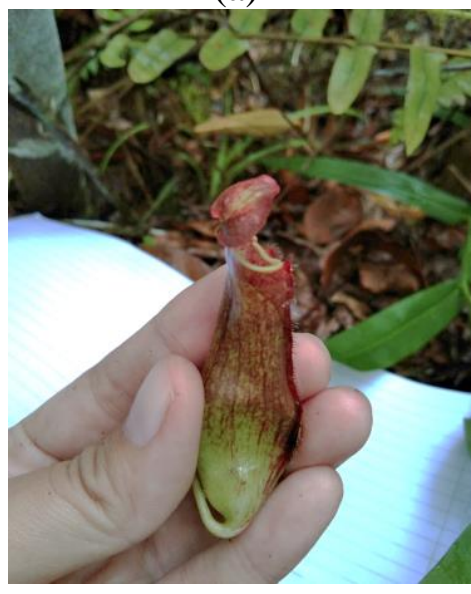

N. xneglecta $(\mathrm{d})$

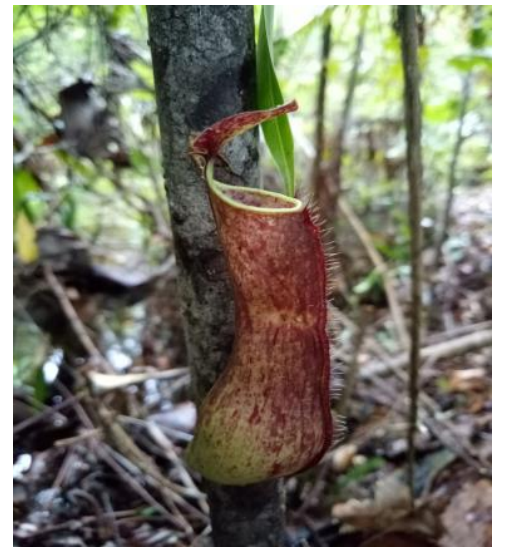

N. gracilis Korth (b)

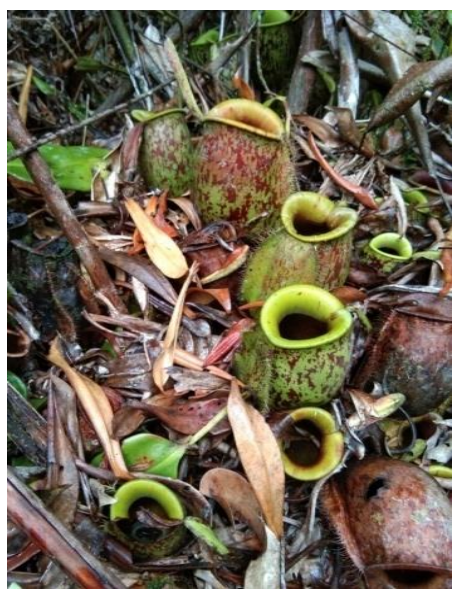

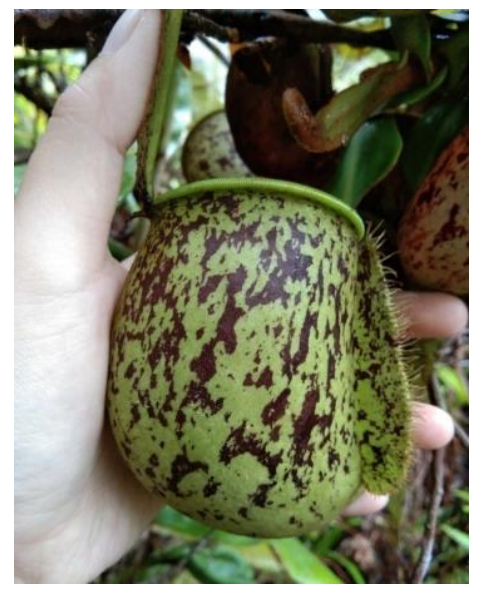

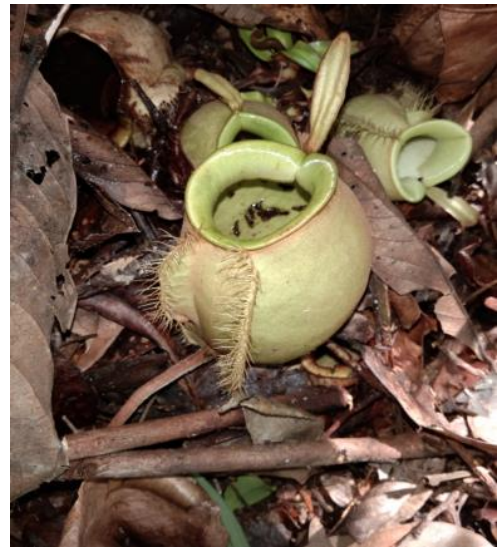

N. ampullaria Jack (c)

N. xhookeriana (e)

Gambar 3. Kharaktersitik Kantong Semar (Nepenthes spp) di Kebun Raya Sambas (Kharaktersitik of kantong semar (Nepenthes spp) in the Sambas Botanical Garden) 
Vegetasi kantong semar (Nepentehs spp) termasuk kelompok tumbuhan bawah, sehingga INP didapat dari penjumlahan nilai Kerapatan Relatif
(KR) dan Frekuensi Relatif (FR). Hasil perhitungan INP kantong semar (Nepenthes sp) dikemukakan pada Tabel 2.

Tabel 2. Indeks Nilai Penting (INP) kantong semar di Kebun Raya Sambas (Important Value Index (IVI) of Kantong Semar at Sambas Botanical Gardens)

\begin{tabular}{clccccc}
\hline Areal & Jenis Individu & Kerapatan/ha & $\mathrm{Kr}$ & Frekuensi & Fr & INP \\
\hline Semak & N.mirabilis & 125 & 1,046 & 0,25 & 14,28 & 15,33 \\
Belukar & (Lour) Druce & & & & & \\
& N. gracilis Korth & 50 & 0,418 & 0,25 & 14,28 & 14,70 \\
& N. ampularia & 9375 & 78,451 & 0,5 & 28,57 & 107,02 \\
& Jack & & & & & \\
& N. xneglecta & 50 & 0,418 & 0,25 & 14,28 & 14,70 \\
& N. xhookeriana & 2225 & 18,619 & 0,25 & 14,70 & 33,32 \\
\hline Terbuka & N.mirabilis & 125 & 1,046 & 0,25 & 14,285 & 15,33 \\
& (Lour) Druce & & & & & \\
\hline
\end{tabular}

Berdasarkan perhitungan Tabel 2, diketahui bahwa penguasaan yang tertinggi pada lahan semak belukar yaitu jenis $N$. ampularia Jack dengan nilai INP 107,02. Tingginya nilai INP ini membuktikan bahwa jenis $N$. ampularia Jack cocok pada kondisi tempat tumbuh areal semak belukar. Besarnya nilai INP $N$. ampularia Jack menunjukan adanya faktor pengaruh lingkungan yang sesuai, sehingga jenis ini mampu untuk berkompetisi dalam memperebutkan zat hara pada lokasi penelitian. Hasil tersebut sama dengan hasil penelitian Suwardi (2015) bahwa jenis $N$. ampullaria di Hutan Rawa Gambut memiliki INP tertinggi dibandingkan dengan jenis Nepenthes lainnya. Hasil perhitungan INP yang paling rendah adalah jenis $N$. gracilis Korth dan $N$. xneglecta rendahnya dengan nilai 14,70 . Nilai INP pada kedua jenis ini dikarenakan sedikitnya jumlah individu yang ditemukan serta faktor tempat tumbuh yang kurang cocok. Odum dalam Amanda (2019) menjelaskan bahwa jenis yang dapat dikatakan mendominasi pada suatu lokasi apabila jenis tersebut berjumlah besar dan tersebar merata hampir di seluruh kawasan.

Hasil indeks dominasi menunjukan bahwa dari kondisi tempat tumbuh yang berbeda pada lokasi penelitian, tidak ada jenis yang mendominansi jenis lainnya, karena nilai hasil perhitungan Nilai Indeks Dominansi masih kurang dari $1 \quad(\mathrm{C}<1)$. Hasil pengamatan memperlihatkan bahwa jenis kantong semar mempunyai kemampuan tumbuh yang cukup baik dan dapat hadir pada kedua habitat (semak dan terbuka). Jenis lain yang mempunyai nilai dominasi tertinggi dari jenis lainnya 
adalah jenis $N$. ampullaria. Ini berati jenis $N$. ampullaria memilik kemampuan untuk bersaing dalam dalam kehidupannya dibandingkan dengam ke empat jenis yang lainnya. Amanda (2019) menyatakan jenis $N$. ampullaria mampu berkompetisi dengan tumbuhan yang ada di sekitarnya untuk mendapatkan unsur hara, cahaya matahari dan air sehingga dapat menguasai tempat tumbuh.

Dari hasil perhitungan terhadap kekayaan jenis dapat diketahui bahwa kantong semar yang tumbuh pada semak belukar memiliki nilai tertinggi, $(\mathrm{D}=1,4954)$, sedangkan pada habitat areal terbuka nilainya sangat rendah (D $=0$ ). Berdasarkan hasil dari indeks kekayaan jenis ini dapat disimpulkan bahwa pada areal semak belukar memiliki kekayaan jenis kantong semar pada areal semak belukar sangat tinggi dibandingkan dengan habitat yang terbuka. Hasil analisis data dalam perhitungan indeks of similarity (IS) membuktikan bahwa kedua areal memiliki vegetasi kantong semar yang tidak sama, dimana dengan nilai indeks yang kurang dari $50 \%$. Suatu penyusun vegetasi dikatakan sama apabila nilai lebih dari $50 \%$. Terjadinya perbedaan jenis antar petak keseluruhan dikarenakan jenis penyusun vegetasi (tumbuhan bawah) terhadap kedua kondisi tempat tumbuh yang berbeda. Perbedaan habitat sangat berpengaruh terhadap jenis vegetasi yang tumbuh.

\section{KESIMPULAN}

1. Hasil studi menunjukkan bahwa keanekaragaman jenis kantong semar
(Nepenthes spp) di Kebun Raya Sambas termasuk kategori rendah dengan nilai pada semak belukar 0,254 , dan areal terbuaka 0,01756 .

2. Terjadi perubahan komposisi jenis kantong semar (Nepenthes spp) setelah dua tahun dari penelitian sebelumnya. Perubahan itu terjadi dimana muncul jenis baru berupa $N$. xneglecta dan N.gracilis Korth dengan jenis yang dominan adalah N.ampullaria Jack.

3. Bedasarkan hasil analisis morfologinya, ditemukan sebanyak 5 jenis kantong semar yang terdiri dari N. mirabilis (Lour) Druce, N.gracilis Korth, N.ampullaria Jack, $N$. xneglecta, $N$. xhookeriana, yang tumbuh di semak belukar, dan $N$. mirabilis (Lour) di areal terbuka.

4. Hasil analisis Indeks Nilai Penting (INP) ternyata jenis N.ampullaria Jack dengan nilai 107,02 dan N. $x$ hookeriana 33,32 menunjukkan bahwa kedua jenis Kantong semar tersebut tumbuh secara dominan terutama pada areal semak belukar.

\section{SARAN}

1. Untuk kepentingan pengetahuan tentang Nephentes spp perlu di teliti lebih lanjut terhadap jenis tanah secara spesifik, $\mathrm{pH}$ tanah, intensitas cahaya, keanekaragaman struktur gen, dan morfologi secara lebih lanjut di Kebun Raya Sambas.

2. Pengelolaan Kebun Raya Sambas di Kecamatan Subah , Kabupaten Sambas perlu di perhatikan untuk Kelestarian flora dan fauna yang ada di dalam kawasan tersebut, 
khususnya Nepenthes spp agar dapat di nikmati keindahannya oleh pengunjung taman dan masyarakat sekitar lokasi Kebun Raya.

\section{DAFTAR PUSTKA}

Amanda, S. M, Astiani D, Muin A.2019.Keanekaragaman Jenis kantong Semar (Nepenthes spp) di Tutupan Lahan Semak Belukar Dan Hutan Sekunder Dusun Gemuruh Kecamatan Selakau Timur Kabupaten Sambas.Jurnal Hutan Lestari. 7 (2) : 844-856.

Dino. 2016. Study of Diversity and Conditions of The Place of Growing Pitcher Plant (Nepenthes Spp) in Sebedang Lake The District of Sebawi Sambas Regency. Jurnal Hutan Lestari.4 (3): 371-379.

Ewusie JY. 1990. Pengantar Ekologi Tropis. ITB Press. Bandung.
Firstantinovi, E. S., dan Karjono. 2006. "Kami justru mendorong". Artikel Majalah Trubus.

Edisi 444. November 2006/XXXVII. Halaman 21.

Hairunnisa, Dewantara. I, Ardian.H. 2018. Keanaekaragaman Jenis Kantong Semar (Nepenthes spp) di Kebun Raya Sambas Kecamatan Subah kabupaten Sambas Kalimantan Barat. Jurnal Hutan Lestari 6 (3) : 519-525.

Sartika, Setiawan. A, Master. J. 2017. Populasi dan Penyebaran Kantong Semar (Nephentesgrscilis) di Rhino Camp Resort Sukaraja Atas Kawasan Taman Nasional Bukit Barisan Selatan. Jurnal Sylva Lestari. 5 (3).

Suwardi, A.B. 2015. Keanekaragaman Jenis Kantong Semar (Nepenthes spp.) di Hutan Rawa Gambut Kalimantan Barat. Jurnal Jeumpa. 2(2): 56-63. 